\title{
O SISTEMA DE GOVERNO PRESIDENCIAL E A REALIDADE BRASILEIRA: CONFORMAÇÕES E DISSENSÕES
}

Rodrigo Valin de Oliveira ${ }^{1}$ Bruno José Queiroz Ceretta ${ }^{2}$

A Presidência da República integra o conjunto das principais instituições brasileiras. Consolidou-se como parte da tradição política do país. Desde certo ponto de vista histórico, tratam-se de realidades facilmente verificáveis. Entretanto, partindo de um exame político e preponderantemente jurídico - que tome a Teoria do Estado e o Direito Constitucional como ferramentas de análise - é possível controverter diferentes aspectos do consenso supostamente existente em torno do sistema presidencial. Com vistas ao aprimoramento da ordem política, cabe questionar a relação entre a formação do país e a configuração jurídica referido do modelo no Brasil.

Palavras-chave: Teoria do Estado; Direito Constitucional; Instituições; Sistemas de Governo; Presidencialismo.

\section{THE PRESIDENTIAL GOVERNMENT SYSTEM AND THE BRAZILIAN REALITY: CONFORMATIONS AND DISSENSIONS}

The Presidency of the Republic is one of the main Brazilian institutions. It was consolidated as part of the political tradition of the country. From a certain historical point of view, this is an easily verifiable reality. However, from a political and predominantly legal examination it is possible to controvert different aspects from the consensus allegedly existing as regards the presidential system. Aiming to improve the political order, we have to call into question the relationship between the formation of the country and the legal configuration of the model in Brazil.

Keywords: Theory of State; Constitutional Law; Institutions; Government Systems; Presidentialism.

\footnotetext{
${ }^{1}$ Doutor em Direito do Estado pela Universidade de São Paulo. Professor de Política e Teoria do Estado da Faculdade de Direito da Universidade Federal do Rio Grande do Sul. E-mail rvalin@uol.com.br

2 Mestrando em Direito pela Universidade Federal do Rio Grande do Sul. Advogado. E-mail brunoceretta@terra.com.br
} 


\section{INTRODUÇÃO}

Instituições definem realidades. Todavia, como encontrar arranjos políticos consentâneos com a pluralidade de cenários existentes? Certamente, inexiste uma resposta incontroversa para circunstâncias e contextos de variegada índole. De fato, conjunturas sociais são singulares e demandam escolhas impossíveis de mero translado. Urge examinar cada panorama e considerar os diferentes fatores existentes.

Este trabalho propõe-se a analisar o sistema de governo presidencial. Encontra nesta temática o seu objeto material. Tendo em vista a amplitude do tema, dirige-se para um recorte específico, a bem dizer, a relação mantida com a conjuntura do país. Especificamente, questiona a conformação do modelo perante a dinâmica brasileira. Tal ângulo de análise figura como objeto formal da pesquisa.

Enquanto instituição, a Presidência da República não foi formulada em termos abstratos, mas, de forma precípua, circunstanciais. Inserta na realidade brasileira, encontrou entraves inexistentes em sua matriz original. Ocorre, sistemas políticos não são simples ícones ou convenções de época. Efetivam processos históricos. Desencadeiam fenômenos de repercussão em toda a sociedade.

O encontro com a Política não é facultativo. Trata-se de necessidade indeclinável para qualquer comunidade assentada em bases civilizacionais mínimas. Importa aprimorar a conjunção política de modo a conciliar os objetivos comumente partilhados com os próprios limites estruturais - sociais, econômicos e culturais - existentes.

O presidencialismo consolidou-se como parte da tradição política brasileira. Está incorporado ao elenco das principais instituições do país. Contudo, não se converteu em elemento impassível de exames e eventuais aperfeiçoamentos. O reconhecimento de seu escopo histórico não implica em aquiescência com aspectos controvertidos e contestáveis.

\section{CARACTERES ESSENCIAIS}


Conforme referido, uma boa ordenação da atividade política - de acordo com os patamares de democracia consensualmente vigentes hoje - depende de instituições, porquanto estas perfazem a operacionalização de nossos sistemas governativos. Trata-se de encadeamento cuja complexidade evidentemente não se exaure na descrição, mas nela pode ser emoldurada, sistematizada, ao menos parcialmente.

Historicamente, diferentes métodos de leitura foram desenvolvidos. Verifica-se uma crescente consciência da interdependência entre os campos político (ou político e jurídico, juspolítico, portanto) e a correspondente ordenação social. ${ }^{3}$ Evidentemente, a Política não abarca toda a dimensão social; por outro lado, o campo social não esgota o complexo político. Há uma conexão dialética permanente entre os setores.

Tais ponderações remetem a antigas reflexões. Aristóteles encabeçou a definição de que o homem é animal político por natureza (anthropos physei politikon zoon). Em seu entendimento, a sociedade - compreendida como polis - é notoriamente política. No momento em que nasceram os primeiros agrupamentos sociais, desenvolveram-se as mais rudimentares instituições:

\footnotetext{
1252a Poichè vediamo che ogni cittá è un'associazione e che ogni associazione è costituita col fine di raggiungere qualche bene (infatti tutti gli uomini compiono qualsivoglia operazione per raggiungere quel che loro sembra bene), è manifesto che, se tutte le associazioni tendono a qualche bene, a più forte ragione vi deve tendere quella che è sovrana tra tutte e tutte le altre comprende: questa è quella che vien chiamata città e associazione politica. ${ }^{4}$
}

O homem partiu para a convivência social com espírito político. Orientou-se também aos objetivos comunitários, pertinentes à generalidade dos cidadãos. Cabe reforçar: escolhas políticas representam necessidade indeclinável. São promovidas consciente e racionalmente, ou de modo mais ou menos dissimulado, amalgamado com desígnios e mesmo valores diversos.

Em observância àquele limiar civilizacional, Fustel de Coulanges ressaltou,

\footnotetext{
${ }^{3}$ Cf. SOUZA JUNIOR, Cezar Saldanha. A Supremacia do Direito no Estado Democrático e seus Modelos Básicos. Porto Alegre: Ed. UFRGS, 2002.

${ }^{4}$ ARISTOTELE. Politica. Tradução de V. Costanzi. 3. Ed. Bari: Giuseppe Laterza \& Figli, 1948, p. 1.
} 
Não se deve representar uma cidade à sua origem deliberando sobre o governo que vai se outorgar, buscando e discutindo suas leis, combinando suas instituições. Não foi assim que leis foram elaboradas e governos foram estabelecidos. As instituições políticas da cidade nasceram com a própria cidade, no mesmo dia que ela. Cada membro da cidade as trazia em si mesmo pois elas se encontravam em germe nas crenças e religião de cada homem. ${ }^{5}$

Trata-se de uma constante. Jamais existirá sociedade - minimamente organizada desprovida de atividade política. Torna-se imediatamente necessário um componente preliminar, constitutivo, garantidor da ordem e das numerosas reivindicações da existência humana. Do contrário, não seria possível falar em comunidade, mas no somatório abstrato e meramente acidental de indivíduos. Neste sentido,

\begin{abstract}
A história não nos proporciona nenhum exemplo de sociedade desprovida de qualquer organização política, ainda que rudimentar. Supor que possa existir sociedade sem organização política, seria crer em uma espontaneidade autorganizadora dela própria. Mesmo para os contratualistas clássicos, como por exemplo Hobbes e Rousseau, o “estado de natureza” anterior à organização política não era um fato histórico ou real. Tratava-se de uma hipótese a que recorriam para, em representando como seria a vida humana fora de uma unidade política, avançarem princípios normativos de como a sociedade deveria ser politicamente reorganizada. ${ }^{6}$
\end{abstract}

Embora não raro velados, dilemas políticos tornam-se evidentes naquelas circunstâncias extremas, mormente vinculadas a crises e mesmo rupturas institucionais. O homem carece de ferramentas para resguardar o convívio social. Logo, o aprimoramento institucional agrega-se ao quadro de interesses gerais da sociedade, pois voltado para o bem comum.

Indispensável controverter e aventar caminhos para a melhor organização das forças políticas e sociais. Encargo partilhado por diferentes setores do conhecimento, toca especialmente ao Direito. Enquanto reflexo de certa unidade epistemológica, a Política também participa do debate - e, como expressão de sinergia entre tais campos, tende a aperfeiçoar ou a entravar as referidas estruturas.

Por oportuno, cabe apresentar um conceito basilar de instituição. Compreende elementochave para a investigação proposta. Em definição de Raquel Sztajn,

\footnotetext{
${ }^{5}$ FUSTEL DE COULANGES, Denis. A Cidade Antiga. Tradução de Edson Bini. 3. Ed. Bauru: Edipro, 1954, p. 153.

${ }^{6}$ SOUZA JÚNIOR, Cezar Saldanha. Consenso e democracia constitucional. Porto Alegre: Sagra Luzzatto, 2002, p. 20-21.
} 
Palavra polissêmica, instituições, do étimo latino institutio, de instituire, significa tanto o ato ou efeito de instituir, criar, fundar, estabelecer alguma coisa duradora, quanto organizar, ordenar. Também é empregada para indicar costumes ou estruturas sociais que modelam práticas aceitas e respeitadas em determinada comunidade ou núcleo social.

Tal multiplicidade de significados tem um eixo ou cerne comum: conjunto de princípios e regras (jurídicas ou não), que configuram relações sociais ou grupo de relações sociais. Por isso, a palavra aparece presa a organizações como associações e sociedades, cujas estruturas se destinam a perdurar, de forma ativa, por largos períodos. [...]

No plano do Direito, a palavra instituição, de que deriva instituto, é, ainda, empregada no sentido de ordenamento jurídico e aqui indica a unificação de elementos diversos que requer um tipo, modelo ou gênero que represente essa unidade. Um dos elementos fundamentais é a duração e a continuidade de uma prática social, de conceitos fundamentais que embasem determinada área de estudo e sobre os quais se apóia a construção subseqüente.

Instituições representam a ordenação sistemática da disciplina, os pilares sobre os quais se erige o edifício lógico-normativo. Afirma-se que onde há Direito há sociedade e, inversamente, que não há sociedade sem Direito, reconhecendo-se, implicitamente, que Direito e sociedade são indissociáveis um do outro: o que é jurídico é social e o que é social é jurídico. ${ }^{7}$

E acrescenta,

\begin{abstract}
Algumas instituições são personificadas, entre elas, por exemplo, o Estado, as sociedades e as associações entre particulares, entre eles e o Estado, e outras que não o são, sem que, por isso, percam o caráter de organização criada para disciplinar interesses sociais. Em comum, essas instituições têm a idéia de organização da atividade a ser desenvolvida por um grupo de pessoas e a imputação de competências, de exercício de poder para realizá-la; a aceitação das regras emanadas desse poder se impõe sobre todos os membros daquele grupo. ${ }^{78}$
\end{abstract}

Seguramente, amplíssimas parcelas da dinâmica política e jurídica, indissociáveis da natureza humana, podem ser examinadas conforme a ótica institucional. Especialmente a operacionalização moderna da atividade política - pautada por princípios, regras e agentes permanece adstrita a tal lógica. Vale refletir: o que são os poderes estatais, senão instituições? O próprio ordenamento jurídico?

Reitera-se pressuposto enunciado. Por expressão e intermédio das instituições operamse as grandes transformações, inclusive no campo social. Não é possível modificar os cânones

\footnotetext{
${ }^{7}$ SZTAJN, Rachel. Law \& Economics. In: ZYLBERSZTAJN, Decio; SZTAJN, Rachel; PINHEIRO, Armando Castelar. Direito \& economia: análise econômica do direito e das organizações. Rio de Janeiro: Elsevier; Campus, 2005, p. 228-229.

${ }^{8}$ Ibidem, p. 230.
}

\title{
Revista Brasileira de Teoria Constitucional | e-ISSN: 2525-961X | Maranhão | v. 3 | n. 2 |
}


institucionais - explícitos ou implícitos, taxativos ou silenciosos, efetivos ou simbólicos - sem deixar de impactar a própria ordem. Convém respeitar este processo.

Finalmente, conjecturar modelos e sistemas revela-se tão estratégico quanto controverter os titulares das funções públicas. Eleitos, não podem ignorar a força das instituições, verdadeiros itinerários jurídicos pontuados por encargos e prerrogativas indeclináveis. Usualmente comportam-se segundo as regras previamente fornecidas. O sistema presidencialista não constitui exceção.

\section{ASPECTOS DA FORMAÇÃO POLÍTICA E SOCIAL DO BRASIL}

Expendidas as considerações iniciais, especialmente voltadas a refletir o escopo juspolítico, cabe remeter o enfoque de apreciação para o Brasil. É apropriado resgatar as linhas gerais da construção institucional nacional, perpassando, conquanto de forma sumária, os intrincados elementos sociais. Importa plasmar os argumentos outrora delineados com a realidade do país.

O exemplo pátrio consiste em um dos paradigmas mais evidentes da precedência política frente aos setores social e econômico. Como sabido, a fundação do país antecedeu a própria composição demográfica. Os donatários foram designados para as capitanias, então desprovidas de qualquer organização social, ainda no século XVI; a Corte lusa desembarcou com todo o corpo burocrático no século XIX; por fim, o ermo Cerrado recebeu a novel capital federal no século XX.

Seja na fase colonial, imperial ou republicana, os ciclos econômicos foram estimulados consoante as aspirações políticas. Em regra, tratou-se do Estado fruído com fins patrimonialistas, tão amplamente observado por Raymundo Faoro ${ }^{9}$ : esforço para alcançar (ou manter) o poder e, a partir dele, promover os arranjos convenientes, imiscuindo interesses públicos e privados, objetivos comuns e estritamente particulares.

\footnotetext{
${ }^{9}$ FAORO, Raymundo. Os donos do poder: formação do patronato político brasileiro. 4. Ed. São Paulo: Globo, 2008.
} 
Para João Camilo de Oliveira Torres,

\begin{abstract}
O Brasil oficialmente entrou a existir quando D. João III, o Povoador, nomeou Tomé de Souza governador-geral do Brasil. Êste fidalgo chegou à Bahia trazendo uma espécie de Constituição para o país, o famoso Regimento do Govêrno, um ministro da Justiça (o ouvidor-mor), um ministro da Fazenda (o provedor-mor), o poder espiritual, no clero, soldados, e fundou a cidade do Salvador, que logo passou a ter, inclusive, uma câmara municipal. Era o Estado do Brasil, que nascia com todos os órgãos que um govêrno que se preza deve ter. Notava-se, apenas, uma ligeira ausência, uma sombra no conjunto: não havia povo. A rigor, não havia o Brasil que o governadorgeral devia governar - um litoral mal conhecido, com alguns pontos de povoamento, alguns postos de contrabandistas, e no interior a mataria selvagem e desconhecida - e índios ferozes. A História tem conhecido casos de precedência ontológica do Estado ao povo - mas, ao povo como entidade organizada, a res publica dos antigos. Sempre havia uma espécie de multidão, amorfa e difusa, sôbre a qual a autoridade se exerceria, consolidando o poder. Mas, no Brasil, o fato realmente espantoso era o da precedência física do Estado ao povo; não havia, a rigor, ninguém para ser governado pelo nosso estimável Tomé de Sousa. Êste famoso "barão assinalado" conheceu um fato que, tirante fábulas antigas, raramente deve ter acontecido: um governante que desembarca no espaço vazio, chegando primeiro que seus governados, e constrói no mato a sua capital.
\end{abstract}

Tivemos o Estado antes de ter povo, esta a verdade. ${ }^{10}$

Neste particular, o comparativo com o processo de formação norte-americano é corriqueiro. Nosso arcabouço político não surgiu como reflexo de estruturas sociais preliminares, mas, pelo contrário, a sociedade esboçou seus traços iniciais a partir das condições proporcionadas pelos ditames estatais. “O Brasil é, assim, uma criação do Estado, obra do 'govêrno’; eis a primeira e mais evidente conclusão a que se chega da análise da história dêste país." 11

Com tais conjunturas em vista, infactível cogitar que florescessem instituições políticas ascendentes. Em realidade, ainda hoje, procedimentos de maior proeminência popular, como plebiscitos e referendos, representam desafio não totalmente superado. O poder proveio de um pequeno grupo e nele tendeu a conservar-se. Na interpretação de Oliveira Viana,

No Brasil, até 1822, em mais de três séculos, não tivemos outro regime senão o do Estado-Império. Os governadores-gerais, os capitães-generais e os vice-reis delegados imediatos do Rei de Portugal - acaudalando o luzido séquito do seu pessoal

\footnotetext{
${ }^{10}$ TORRES, João Camilo de Oliveira. Interpretação da realidade brasileira: introdução à história das idéias políticas no Brasil. Rio de Janeiro: José Olympio, 1969, p. 28-29.

${ }^{11}$ Ibidem, p. 63.
} 
burocrático, do seu pessoal militar, dos seus comandantes de tropas, e dos seus ouvidores-gerais e de comarca, e dos seus juízes de fora, e todos os demais funcionários da alta administração, mesmo local, não eram eleitos pelo povo da Colônia e das suas localidades; mas, nomeados e investidos pelo Rei ou em nome dele.

Havia, é certo, as câmaras municipais, com os seus vistosos senados e vereadores, juízes e procuradores; mas, estas corporações, no período colonial, não eram, nem nunca foram, organizações de tipo democrático; eram corporações de tipo oligárquico e aristocratizado, não tendo o povo - como elemento de expressão da massa nenhuma participação nelas. ${ }^{12}$

Entretanto, tais delineamentos políticos também têm a ver com a forma de ocupação do território. Pequenos contingentes gradualmente desenvolveram-se em pontos esparsos - junto aos quais outras minorias deliberavam acerca dos temas de interesse coletivo. Os agrupamentos inclinavam-se à autossuficiência e ao isolamento econômico, como se bastassem a si, preterindo a comunicação e o próprio intercâmbio comercial. ${ }^{13}$

Para Caio Prado Junior, emergiu, naqueles primeiros tempos, uma vasta empresa comercial. ${ }^{14}$ Não pela rara mercancia, mas por um destacado potencial produtivo que começava a explorado. Referiu-se à propriedade açucareira como "um verdadeiro mundo em miniatura em que se concentra e resume a vida toda de uma pequena parcela da humanidade.” ${ }^{15}$

Os detentores de poder político asseguraram o correspondente predomínio econômico. Paralelamente, a maior parte da população permaneceu irredutivelmente alheia. Consolidaramse distanciamentos. ${ }^{16}$ Longe de qualquer predomínio que redundasse em segregação estrita, o componente demográfico foi indelevelmente marcado por uma profunda amalgamação étnica e cultural. Para Gilberto Freyre:

\footnotetext{
${ }^{12}$ OLIVEIRA VIANA, Francisco José de. Instituições políticas brasileiras. Brasília: Senado Federal, 1999, p. 146.

${ }^{13}$ Enquanto o meio social urbano volta-se costumeiramente para o desenvolvimento da política e do comercio, tais atividades não recebem estímulo idêntico no cenário rural. Sérgio Buarque de Holanda comenta o forte caractere agreste presente na trajetória brasileiras (HOLANDA, Sérgio Buarque de. Raízes do Brasil. 26. Ed. São Paulo: Companhia das Letras, 1995, p. 73; OLIVEIRA VIANA, Francisco José de. Instituições políticas brasileiras. Brasília: Senado Federal, 1999, p. 162).

${ }^{14}$ PRADO JUNIOR, Caio. História Econômica do Brasil. São Paulo: Brasiliense, 2008, p. 23.

${ }^{15}$ Ibidem, p. 38.

${ }^{16}$ Entretanto, não se pode afirmar que o processo de ocupação foi pautado apenas por equívocos. Decisões e escolhas não decorreram de raciocínios aprioristas, mas com espírito pragmático, cujos reflexos alcançam o Brasil contemporâneo (HOLANDA, Sérgio Buarque de. Raízes do Brasil. 26. Ed. São Paulo: Companhia das Letras, 1995, p. 109).
} 
Formou-se na América tropical uma sociedade agrária na estrutura, escravocrata na técnica de exploração econômica, híbrida de índio - e mais tarde de negro - na composição. Sociedade que se desenvolveria defendida menos pela consciência de raça, quase nenhuma no português cosmopolita e plástico, do que pelo exclusivismo religioso desdobrado em sistema de profilaxia social e política. Menos pela ação oficial do que pelo braço e pela espada do particular. ${ }^{17}$

Não seria despropositado ponderar de que forma o conjunto de elementos - sociais, econômicos, culturais, ora apresentados - relaciona-se com o modelo presidencial. Longe de figurativos, tais fatores compõem o plano de fundo do sistema político. Na medida em que as ideias políticas não sobrevivem abstratamente, mas inter-relacionam-se com a dinâmica histórica, demandam compatibilidade.

Embora as instituições políticas orientem um conjunto de práticas, carecem, por outro lado, de respaldo social. Resguardados determinados limites, não podem desconhecer ou colidir com os modos de conformação da população. É indispensável referir tais aspectos, mesmo por meio de recortes, dado o diálogo intrínseco com o sistema político.

Uma compreensão não exatamente moderna, direcionada para a autonomia individual e coletiva, mas atrelada às formas mais tradicionais de autoridade, de acordo com relações de dependência, caracteriza o exercício do poder político no Brasil. ${ }^{18}$ Tais fatores influem na prática do sistema presidencialista, cujo grande poder depositado no mandatário reflete em toda sociedade política.

\section{SISTEMA PRESIDENCIAL E DINÂMICA INSTITUCIONAL NO BRASIL}

Possivelmente, a contribuição mais relevante a ser dada pela Teoria do Estado e o Direito Constitucional consiste na concepção de um modelo funcional de Estado: ignorados determinados patamares de racionalidade, inexistirá ordem, tampouco os almejáveis direitos

\footnotetext{
${ }^{17}$ FREYRE, Gilberto. Casa-grande \& Senzala: Formação da família brasileira sob o regime da economia patriarcal. 48. Ed. São Paulo: Global Editora, 2003, p. 65.

${ }^{18}$ Gilberto Freyre também reconhece pontos positivos na formação do país (FREYRE, Gilberto. Casa-grande \& Senzala: Formação da família brasileira sob o regime da economia patriarcal. 48. Ed. São Paulo Global Editora, 2003, p. 43; p. 73-74).
}

\section{Revista Brasileira de Teoria Constitucional | e-ISSN: 2525-961X | Maranhão | v. 3 | n. 2 |}


constitucionais. Intenções são insuficientes. Solenes declarações não efetivam programas políticos.

Categorias convertidas em direitos constitucionais - como reunião ${ }^{19}$, associação ${ }^{20}$ ou segurança ${ }^{21}$ - não são definições que subsistem abstratamente. Deprecam forte background institucional. Do contrário, persistem textos legislativos de profunda conotação retórica, mesmo, por vezes, inspiradora, mas de aplicabilidade nula, falha ou visivelmente questionável.

Os Estados ocidentais desenvolvidos atingiram determinados pontos consensuais. Em que pese a formação histórica reciprocamente distinta, cânones fundamentais foram gradualmente recolhidos. Inexiste um modelo universal de Estado, mas, seguramente, diferentes experiências apontam para axiomas e instituições hoje conjuntamente reconhecidas.

Tais realidades orientam-se sob um Texto Constitucional amparado na adesão dos cidadãos. Limitam os poderes dos mandatários, impondo-lhes deveres e responsabilidades. Repartem as funções estatais. Por fim, asseguram direitos fundamentais. O encadeamento não é mera casualidade. Corresponde a uma série de necessidades recíprocas.

Especificamente, verifica-se uma divisão do próprio poder central do Estado. Sejam republicanas ou monárquicas, federadas ou unitárias, tais unidades políticas normalmente distinguem o campo de Estado daquele de Governo: o primeiro, pertinente ao Chefe de Estado, resguarda a globalidade da comunidade política; o segundo, relativo ao Chefe de Governo, dirige-se para a parcela eleitoralmente vitoriosa. ${ }^{22}$

O modelo presidencial cumula as funções. Compete ao Presidente dirigir pautas de Estado, mas também de Governo. Volta-se para tópicos de interesse comum enquanto delibera em matérias estritamente parciais, controversas, passíveis de amplos questionamentos. Em esforço inaudito, propõe-se a representar o país externamente; contudo, de maneira contraditória, também a parcela ideologicamente predominante. ${ }^{23}$

\footnotetext{
${ }^{19}$ Art. 5, XVI da Constituição Federal de 1988.

${ }^{20}$ Art. 5º XVII da Constituição Federal de 1988.

${ }^{21}$ Art. $6^{\circ}$ da Constituição Federal de 1988.

22 FERREIRA FILHO, Manoel Gonçalves. Comentários à Constituição brasileira de 1988. São Paulo: Saraiva, 1997. V. 2, p. 151.

${ }^{23}$ SOUZA JUNIOR. Cezar Saldanha. A Crise da Democracia no Brasil. Rio de Janeiro: Forense, 1978.
} 
Cabe confrontar este cenário institucional com os indicadores descritos no capítulo precedente. Em país de formação tão complexa, a proposta costuma testar seus limites estruturais com grande facilidade. Eleito, o titular da função presidencial exerce amplo poder, cujas conexões perpassam diferentes níveis de influência direta e indireta na direção da unidade política.

Consoante aludido, inexiste uma cultura democrática ascendente, desde as pequenas células populacionais. Historicamente, predomina não raro clientelismo, acrescidos a rompantes autocráticos cujos extremos podem romper a ordem jurídica sem maiores impedimentos. O cenário de nascimento do mecanismo presidencialista é distinto - talvez oposto - daquelas realidades para as quais foi transplantado.

Em definição atual de Juan Linz,

\begin{abstract}
El pueblo elige directamente a un Ejecutivo al que la Constitución otorga poderes considerables, generalmente con control total de la composición de su Gabinete y de la administración, por un período de tiempo determinado, y que no depende de un voto formal de confianza de los parlamentarios elegidos democráticamente. El es no sólo el jefe del Poder Ejecutivo, sino la cabeza simbólica del Estado, y no puede ser depuesto, excepto en el caso excepcional de "impeachment" (inicio político) entre elecciones. En la práctica, como muestra una historia de los Estados Unidos, los sistemas presidenciales pueden ser más o menos dependientes de la cooperación de los parlamentarios elegidos para el Congreso y, por lo tanto, presentan variaciones considerables en el equilibrio entre el Poder Ejecutivo y el Legislativo. ${ }^{24}$
\end{abstract}

O poder presidencial é normalmente limitado pelo Parlamento. Segundo Linz, o equilíbrio entre os Poderes Executivo e Legislativo, Presidente da República e Parlamento, respectivamente, adquire densidade estratégica. Certamente, com contornos muito mais rígidos que em uma democracia parlamentar: um impeachment gera maior impacto que uma moção de desconfiança.

Reitera-se que o sistema presidencial não foi cogitado em termos genéricos ou universais. Idealizado no contexto norte-americano, buscou atender aos desafios daquele novel

\footnotetext{
${ }^{24}$ LINZ, Juan J. Democracia: presidencialismo o parlamentarismo ¿Hace alguna diferencia? In: LINZ, Juan J.; LIJPHART, Arend; VALENZUELA, Arturo; ARCAYA, Oscar Godoy. Hacia una democracia moderna: la opción parlamentaria. Santiago: Ediciones Universidad Católica de Chile, 1990, p. 47.
} 
país, então imerso em seus debates constituintes ${ }^{25}$ Foi conjecturado em vista de uma realidade particular, concreta, claramente delimitada. Robert Dahl descreve o processo:

O governo presidencialista foi inventado pelos delegados presentes na Convenção Constitucional dos Estados Unidos em 1787. A maioria dos delegados admirava a Constituição britânica (não-escrita) por sua “separação dos poderes” em um Judiciário independente tanto do Legislativo quanto do Executivo; um Legislativo (o Parlamento) independente do Executivo; e um Executivo (a monarquia) independente do Legislativo. Os delegados procuravam emular as virtudes da Constituição britânica, mas a monarquia estava completamente fora de questão: viram-se perplexos com o problema do Executivo. Sem nenhum modelo histórico importante a utilizar como base, lutaram com a questão por quase dois meses, antes de encontrar a solução.

Embora aquela convenção tenha sido uma extraordinária reunião de talentos constitucionalistas, a passagem do tempo dotou os delegados de uma visão de futuro bem maior do que nos revelam os registros históricos ou do que a falibilidade do ser humano nos permitiria imaginar. ${ }^{26}$

Desde o momento em que foi inserto na Constituição norte-americana, o modelo presidencial perpassou por mudanças. Jamais restou inerte, como se subsistisse autônomo diante das tendências que envolveram igualmente os outros poderes. ${ }^{27}$ Acrescenta-se a influência impressa por muitos presidentes no exercício da função. ${ }^{28}$ Em síntese, confirmou a regra de que as instituições se manifestam historicamente.

Em certo momento daquela Constituinte, as preocupações gravitaram muito mais em torno do Senado, postergando a Presidência da República. ${ }^{29}$ Desse modo, não seria impertinente objetar como o modelo fixou raízes na cultura política dos Estados Unidos. Tendo em vista a dimensão com que o governo é desempenhado nas repúblicas latino-americanas, comenta Giovanni Sartori:

O sistema norte-americano funciona (à sua maneira), porque os americanos estão determinados a fazê-lo funcionar. É simplesmente isto e, pela mesma razão, aí reside a maior dificuldade: os Estados Unidos possuem uma maquinaria constitucional

\footnotetext{
${ }^{25}$ É amplo o resgate de MCDONALD, Forrest. Novus Ordo Seclorum: The Intellectual Origins of the Constitution. Lawrence: University Press of Kansas, 1985, p. 225-260.

${ }^{26}$ DAHL, Robert. Sobre a democracia. Tradução de Beatriz Sidou. Brasília: Universidade de Brasília, 2001, p. 139-140.

${ }^{27}$ ZIPPELIUS, Reinhold. Teoria Geral do Estado. Tradução de António Cabral de Moncada. 2.ed. Lisboa: Fundação Calouste Gulbenkian, 1984, p. 195.

${ }^{28}$ TORRES, João Camilo de Oliveira. O presidencialismo no Brasil. Rio de Janeiro: Edições O Cruzeiro, 1962, p. 57.

${ }^{29}$ MCDONALD, Forrest. Op.cit., p. 249-250.
}

\section{Revista Brasileira de Teoria Constitucional | e-ISSN: 2525-961X | Maranhão | v. 3 | n. 2 |}


voltada para produzir complicações, um defeito que mostra a sua força quando esse tipo de presidencialismo é exportado. ${ }^{30}$

Há de reconhecer-se o êxito daqueles fundadores: dentre outros triunfos, entregaram a condução do governo para um único homem sem que jamais desencadeasse despotismo. ${ }^{31}$ Forrest McDonald entende que o êxito pode ser atribuído a certa sincronia entre diferentes pontos da comunidade política:

And in a ultimate sense the Constitution did reflect a Montesquieuan principle, perhaps the most fundamental of them all: it provided for a government that would itself be governed by laws, and by laws that conformed to the genius and circumstances of the people. ${ }^{31}$

Trata-se de cenário peculiar. O Presidente da República ateve-se preponderantemente às atribuições de Estado (e não de governo). O inverso do Brasil: nossas estruturas políticas e sociais perseguiram lógica diversa, caracterizadas por dirigismo acentuado, não raramente imiscuindo interesses setoriais e comunitários, preterindo, não raro, o bem comum.

O copioso rol de atribuições consignado no art. 84 da Constituição Federal é prova inconteste do dirigismo efetivo e simbólico. ${ }^{32}$ Entretanto, a inserção constitucional do elenco revela-se insuficiente. Como exposto, o Presidente carece de suporte congressual. Os poderes não se bastam solitariamente. Encontram-se interligados. Embora o modelo presidencial dispense maior conectividade com o Poder Legislativo, não possui independência irrestrita frente ao mesmo.

Gianfranco Pasquino tece considerações sobre essa relação. Em observância ao presidencialismo norte-americano, enuncia dilema presente no Brasil:

El principal problema del presidencialismo, en particular del estadunidense, consiste en la presencia en funciones de un presidente cuyo partido no tenga la mayoría en las dos ramas del congreso. En este caso el presidencialismo origina lo que se define

\footnotetext{
${ }^{30}$ SARTORI, Giovanni. Engenharia constitucional. Tradução de Sérgio Bath. Brasília: Editora da Universidade de Brasília, 1996, p. 107.

${ }^{31}$ TORRES, João Camilo de Oliveira. O presidencialismo no Brasil. Rio de Janeiro: Edições O Cruzeiro, 1962, p. 55.

${ }^{31}$ MCDONALD, Forrest. Novus Ordo Seclorum: The Intellectual Origins of the Constitution. Lawrence: University Press of Kansas, 1985, p. 260.
} 
como gobierno dividido. En verdad, algunos estudiosos han visto en la forma presidencial de gobierno también otro peligro: el de un presidente que tenga una sólida mayoría en el congreso y que, por lo tanto, pueda gobernar aplastando la oposición. En el contexto estadunidense se ha hablado al respecto de "presidencia imperial". El presidencialismo estaría sujeto a oscilaciones de un exceso de poder a una carencia de poder, del máximo grado de capacidad decisoria a la parálisis decisoria, del gobierno imperial al gobierno dividido. Naturalmente, algunos de estos afectos pueden ser exacerbados o moderados por el sistema partidista. ${ }^{32}$

O preenchimento do Parlamento brasileiro não opera com uma lógica ascendente. Parcelas eleitorais não indicam e fiscalizam efetivamente seus representantes, pois prevalece uma imprecisão que percorre a imensidão dos limites geográficos de cada Estado. Não há zonas eleitorais específicas. Logo, a relação entre a Presidência da República e o Congresso também se reveste de riscos intrínsecos.

O modelo presidencial conserva visível rigidez nas relações entre os Poderes Executivo e Legislativo. O governante possui mandato previamente definido, mas, ainda assim, carece de suporte legislativo. Por outro lado, o Parlamento pode pressionar o Executivo - embora não obtenha meios para encerrar o período de governo, ressalvada a hipótese extrema de impeachment. Um sistema de governo equilibrado deve considerar a flexibilidade,

[...] la rigidez institucional no es nunca un elemento positivo en ningún sistema político, ya que corre el riesgo de hacer oscilar el sistema entre una crisis, justamente sistémica, y una parálisis igualmente sistémica. En cambio, la flexibilidad, que también implica cambios no solo de los primeros ministros sino también de mayorías parlamentarias, además de ser constitutiva de los modelos parlamentarios de gobierno es, en determinadas condiciones, pero muy frecuentemente, una válvula de seguridad, un mecanismo homeopático y re-equilibrante que mantiene en funcionamento el sistema político. ${ }^{33}$

Com o presidencialismo, uma visão partidária usualmente prepondera com estabilidade. O amparo na previsibilidade temporal do mandato assegura o exercício do poder pelo mesmo grupo. Em regra, o governo será exercido por minorias organizadas. O desafio democrático especialmente no Brasil - consiste em alternar tais conjuntos, impedindo formações oligárquicas. ${ }^{34}$ Daí a tão desejável reforma das instituições. Para Gianfranco Pasquino,

\footnotetext{
32 PASQUINO, Gianfranco. Nuevo curso de ciência política. Tradução de Clara Ferri. México: FCE, 2011, p. 249-250.

${ }^{33}$ PASQUINO, Gianfranco. Los poderes de los jefes de gobierno. Prometeo Libros, 2007, p. 15.

${ }^{34}$ PASQUINO, Gianfranco. Nuevo..., p. 225.
} 
Justamente porque es cierto que buenas instituciones crean las condiciones para una democracia aceptable, aunque luego son los liderazgos políticos las que llevan a cabo todas sus potencialidades (parafraseo a Huntington), parece oportuno y, quizás, decisivo, reformar muchas de las reglas, de los procedimientos y de las instituciones tal como fueron configuradas durante na transición italiana. ${ }^{36}$

Fora do espaço político norte-americano, bastante conhecidos os problemas enfrentados pelo sistema presidencialista, notabilizado por crises e rupturas institucionais. ${ }^{37}$ Aprimorar instituições não implica em reinventá-las, mas considerar nuances presentes em cenários específicos. É possível avançar no debate constitucional velando por essa premissa.

\section{CONCLUSÃO}

A Política não exaure o campo jurídico. O Direito igualmente conta com limitações frente aos elementos políticos. Os componentes político e jurídico inter-relacionam-se em sua complementariedade recíproca. Cabe considerar este cenário como premissa, pois, dada a natureza política do homem, não há como evadir-se dos desafios institucionais.

Todo debate político prescinde de exame do contexto intrínseco. No caso brasileiro, deve-se empreender esforço para refletir a organização política à luz de experiência que soma mais de quinhentos anos. Compete examinar a conjuntura juspolítica sobriamente. O sistema presidencialista - cujo traço definidor é o poder simbólico e expresso depositado no mandatário maior - deve ser analisado de acordo com esta perspectiva.

O convívio político brasileiro não se assentou em patamares de neutralidade e circunscrição entre os âmbitos público e o privado. Inversamente, numerosos os vínculos construídos sob o prisma de categorias tradicionais. Definitivamente, o poder político não

\footnotetext{
${ }^{36}$ PASQUINO, Gianfranco. Los poderes..., p. 15.

${ }^{37}$ SARTORI, Giovanni. Engenharia constitucional. Tradução de Sérgio Bath. Brasília: Editora da Universidade de Brasília, 1996, p. 101.
}

\section{Revista Brasileira de Teoria Constitucional | e-ISSN: 2525-961X | Maranhão | v. 3 | n. 2 |}


emergiu em termos modernos - cenário diverso daquele em que a fórmula presidencialista foi conjecturada.

Não se trata de uma democracia ascendente, como nos Estados Unidos. O poder foi conduzido por pequenos grupos organizados, embora nem sempre unânimes ou mutuamente concordantes. Importa reconhecer tais fatores para adequadamente desenhar um sistema político que compatibilize os elementos políticos e jurídicos com os fatores históricos, tendo em vista os objetivos da própria comunidade política.

Em que pese a mencionada diversidade de arranjos, determinados consensos emergiram nas democracias ocidentais. Repartiram-se as funções, separando as atribuições de Estado daquelas de Governo. O êxito do presidencialismo nos Estados Unidos toca às condições daquele país, singulares e diferentes daquelas encontradas no Brasil. Tais fatores merecem reflexão conjunta. 
O SISTEMA DE GOVERNO PRESIDENCIAL E A REALIDADE BRASILEIRA: CONFORMAÇÕES E DISSENSÕES

\section{REFERÊNCIAS}

ARISTOTELE. Politica. Tradução de V. Costanzi. 3. Ed. Bari: Giuseppe Laterza \& Figli, 1948. BRASIL. Constituição Federal de 1988. Disponível em: $<$ http://www.planalto.gov.br/ccivil_03/Constituicao/Constituicao.htm>. Acesso em: 19 jul. 2017.

DAHL, Robert. Sobre a democracia. Tradução de Beatriz Sidou. Brasília: Universidade de Brasília, 2001.

FAORO, Raymundo. Os donos do poder: formação do patronato político brasileiro. 4. Ed. São Paulo: Globo, 2008.

FERREIRA FILHO, Manoel Gonçalves. Comentários à Constituição brasileira de 1988. São Paulo: Saraiva, 1997. V. 2.

FREYRE, Gilberto. Casa-grande \& Senzala: Formação da família brasileira sob o regime da economia patriarcal. 48. Ed. São Paulo: Global Editora, 2003.

FUSTEL DE COULANGES, Denis. A Cidade Antiga. Tradução de Edson Bini. 3. Ed. Bauru: Edipro, 1954.

HOLANDA, Sérgio Buarque de. Raízes do Brasil. 26. Ed. São Paulo: Companhia das Letras, 1995.

LINZ, Juan J. Democracia: presidencialismo o parlamentarismo ¿Hace alguna diferencia? In: LINZ, Juan J.; LIJPHART, Arend; VALENZUELA, Arturo; ARCAYA, Oscar Godoy. Hacia una democracia moderna: la opción parlamentaria. Santiago: Ediciones Universidad Católica de Chile, 1990.

MCDONALD, Forrest. Novus Ordo Seclorum: The Intellectual Origins of the Constitution. Lawrence: University Press of Kansas, 1985, p. 249-250.

MIRANDA, Jorge. Teoria do Estado e da Constituição. 3. Ed. Rio de Janeiro: Forense, 2011. OLIVEIRA VIANA, Francisco José de. Instituições políticas brasileiras. Brasília: Senado Federal, 1999.

PASQUINO, Gianfranco. Nuevo curso de ciência política. Tradução de Clara Ferri. México: FCE, 2011.

. Los poderes de los jefes de gobierno. Tradução de Luciana Gil e Martín Obaya. 
Buenos Aires: Prometeo Libros, 2007.

PRADO JUNIOR, Caio. História Econômica do Brasil. São Paulo: Brasiliense, 2008.

SARTORI, Giovanni. Engenharia constitucional. Tradução de Sérgio Bath. Brasília: Editora da Universidade de Brasília, 1996.

SOUZA JUNIOR. Cezar Saldanha. A Crise da Democracia no Brasil. Rio de Janeiro: Forense, 1978.

A Supremacia do Direito no Estado Democrático e seus Modelos Básicos. Porto Alegre: Ed. UFRGS, 2002.

. Consenso e democracia constitucional. Porto Alegre: Sagra Luzzatto, 2002.

SZTAJN, Rachel. Law \& Economics. In: ZYLBERSZTAJN, Decio; SZTAJN, Rachel; PINHEIRO, Armando Castelar. Direito \& economia: análise econômica do direito e das organizações. Rio de Janeiro: Elsevier; Campus, 2005.

TORRES, João Camilo de Oliveira. Instituições políticas e sociais do Brasil. São Paulo: Editora Coleção F.T.D, 1965.

Interpretação da realidade brasileira: introdução à história das idéias políticas no Brasil. Rio de Janeiro: José Olympio, 1969.

. O presidencialismo no Brasil. Rio de Janeiro: Edições O Cruzeiro, 1962.

ZIPPELIUS, Reinhold. Teoria Geral do Estado. Tradução de António Cabral de Moncada. 2.ed. Lisboa: Fundação Calouste Gulbenkian, 1984. 